\title{
A Problem in Extralateral Rights on Secondary Veins'
}

\author{
(Copyright, 1913, by Curtis H. Lindley.)
}

While the federal statute regulating the location of veins or lodes was unquestionably constructed with but a single vein in contemplation in the original instance, the law recognizes that there may be found veins apexing within the location other than the one originally discovered and upon which the location is primarily predicated. Such additional veins are usually called secondary veins to distinguish them from the original discovery or primary vein on which the location is based. When the secondary veins are parallel to the discovery vein and with the discovery vein extend throughout the claim from end line to end line there is little room for controversy as to the bounding planes which define the extralateral right on such secondary veins. Under such circumstances they are coincident with the planes measuring the rights on the primary vein. Very often, however, secondary veins exhibit erratic tendencies and as far as direction and extent of apex within the location is concerned, deviate widely from the discovery vein. This complex situation has been discussed in a number of earlier cases. ${ }^{2}$

The Walrath-Champion case last cited has provoked considerable discussion. ${ }^{3}$

1 This discussion is taken substantially from the third edition of Lindley on Mines, the major portion of which work is now in press and which will appear during the Fall of this year. We have been permitted to publish this article through the courtesy of Curtis $\mathrm{H}$. Lindley, Esq., the author and Bancroft Whitney Co., Iaw Publishers.

2 Iron Silver Mining Co. v. Elgin Mining etc., Co., 118 U. S. 196, 207; Consolidated Wyoming $M$. Co. v. Champion M. Co. 63 Fed. 540; Walrath v. Champion M. Co. (commonly called the Providence case) 63 Fed. 552; 72 Fed. 978; 171 U. S. 293.

3 "A Problem in Mining Law," Harvard Law Review, Dec. 1902, Vol. 16 pp. 94, 107; "Extralateral Rights" etc. California Law Review, May, 1913, Vol. I No. 4 pp. 351-352. Costigan on Mining Law pp. 444-449; Lindley on Mines (2nd ed.) 593. 
It is generally agreed that the effect of that decision as far as the determination of the extent of extralateral rights on secondary veins is concerned, is a matter of considerable doubt.

Several interesting cases have arisen in Colorado since the decision in the Walrath-Champion case, which involve the question here discussed. The first of these in chronological order is the case of Ajax Gold Mining Co. v. Hilkey, ${ }^{4}$ the facts of which are illustrated by a diagram accompanying the opinion of the court, which we herewith reproduce as Figure No. 1.

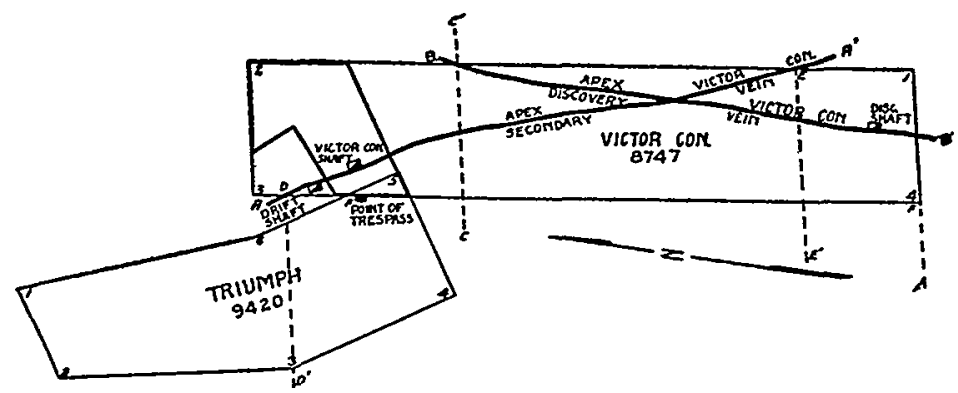

Figure No. 1.

The Ajax company owned the Victor Consolidated claim. The discovery vein $\mathrm{B}^{-} \mathrm{B}^{\prime}$ crossed the southerly end line and proceeding in a northerly direction passed out of the east sideline. The secondary vein $A-A^{\prime}$ passed diagonally through the claim crossing both side-lines. The defendant Hilkey owned the Triumph adjoining the Victor on the west. The secondary vein in the Victor on its downward course entered underneath the surface of the Triumph, and the controversy was over the ore bodies underneath the surface of this claim. The Ajax company claimed that its extralateral right in the secondary vein was to be defined by the application of the plane $D-D$ : parallel to the end-line on the original vein $1-4$ at the point where the vein crossed the west side-line of the Victor. The Triumph owner contended that as the extralateral right on

431 Colo. 131, 102 Am. St. Rep. 23, 72 Pac. 447, 22 Morr. Min. Rep. 585, 62 I. R. A. 555. 
the original lode was to be defined and limited by the plane $\mathrm{C}-\mathrm{C}^{\prime}$ drawn through the point where the discovery vein passed out of the east side-line-the plane being parallel to the south endline-that no extralateral right in the secondary vein could extend northerly beyond the plane C-C.

The court upheld the contention of the Ajax company applying the plane D-D.' In rendering its decision it said in part:-

In the Walrath case, which was twice before the circuit court of appeals 5 and once before the supreme court of the United States, there are some expressions in the opinions of the circuit court of appeals from which, taken alone, it might be inferred that under facts like those here present the owner of a claim would have extralateral rights in the discovery vein even beyond the point where, on its strike, it leaves the side-line; and that the bounding planes, within which such rights are to be exercised, must be drawn through the. two end-lines. But appellant makes no such contention here, and is content with extralateral rights in the discovery vein only up to the point of its departure from the east side-line, so that for our present argument we assume that to be the true doctrine. ${ }^{6}$

After placing the responsibility for the rule applied by it upon the concession of counsel, who declined to claim more of the vein than the application of this rule would award to his clients, the court proceeds to enunciate principles which clearly demonstrate that it was the only rule which could possibly be applied without violating some of the cardinal principles established by the courts of last resort. We quote further from the opinion of the court.-

The end-line constitutes a barrier, beyond which a locator cannot follow a vein on its strike, whether it be a discovery or secondary vein; and they also limit the bounding planes within which his extralateral rights are to be exercised in following stch vein on its dip beyond the bounding

5 This is a mistake. The opinion in 63 Fed. 552, 18 Morr. Min. Rep. 113, is that of the trial court. The circuit court of appeals handed down only one cpinion-72 Fed. 978 (63 Fed. 552, 19 C. C. A. 323; 72 Fed. 978).

62 Pac. 449. 
planes drawn through the end-lines. The extent of the right depends upon the length of the apex, and the extralateral rights are measured not necessarily by the end-lines, and only so when the vein passes across both end-lines, but by bounding planes drawn parallel to the end-lines passing through the claim at the points where it entered and departs from the same. It would seem, therefore, necessarily to follow that the extralateral right depends inter alia upon the extent of the ${ }^{7}$ apex within the surface lines, and, while the end-lines of the claim as fixed by the location are the endlines of all veins apexing within its exterior boundaries, the planes which bound such rights of different veins may be as different as the extent of their respective apices, though all such planes must be drawn vertically downward parallel with the end-lines. It makes no difference in what portion of the patented claim the apex is. Its extralateral rights under this rule can easily be ascertained.

The court was of the opinion that the rule thus enunciated was deducible from the Niagara-Black Rock case, ${ }^{8}$ the decision in Tyler v. Last Chance M. Co., ${ }^{9}$ and from the language of Judge Hallett in the Del Monte case. ${ }^{10}$

The opinion of Justice Brewer in the Del Monte case ${ }^{11}$ is also said by the supreme court of Colorado to be authority for the conclusions reached by it, which are briefly summed up at the end of the opinion as follows:-

Our conclusion is that for all veins, both discovery and secondary of a patented claim, the owner has extralateral rights at least for so much thereof as apex within the surface lines; that such rights as to secondary veins are not confined to such veins as apex within the same segment of the claim in which the apex of the discovery vein exists; and while the end-lines of the location as fixed and described in the patent are the end-lines of all veins apexing within

7 Id. 449.

${ }^{8}$ Fitzgerald v. Clark, 17 Mont. 100, 52 Am. St. Rep. 665, 42 Pac. 273,30 L. R. A. 803 , affirmed in 171 U. S. 92, 18 Sup. Ct. Rep. 941, 42 L. ed. 87.

971 Fed. 848.

1066 Fed. 212.

11171 U. S. 55, 18 Sup Ct. Rep. 895, 43 L. ed. 72. 
the surface boundaries, and may constitute the bounding planes for such extralateral rights, and in no case can the locator pursue the vein on its dip outside the surface lines beyond such planes continued in their own direction until they intersect such veins, yet these bounding planes, which in all cases must be drawn parallel to the end-lines, need not be coincident.12

Subsequent to the rendition of this decision. the same court, in the case of Jefferson Min. Co. v. Anchoria-Leland M. \& M. Co. ${ }^{13}$ was called upon to consider a state of facts involving the same principles discussed and decided in the Ajax-Hilkey case. We submit a diagram of the JeffersonAnchoria-Leland case (Figure No. 2), based upon the one accompanying the opinion of the court slightly elaborated. The Anchoria-Leland company owned the Anchor, and the Jefferson company the Mattie $L$. The Anchor was the senior of the claims both as to location and patent. The discovery vein $Y-Z-Y$ in the Anchor crossed both end-lines, although the fact does not appear on the diagram in the opinion. The secondary vein in the Anchor $a-b$ crossed two side-lines. Both the discovery and secondary veins in the Mattie $L$. crossed the lines located as side-lines. The vein $a-b$ was secondary in both locations. The controversy arose over the under-ground parts of the secondary vein lying underneath within the conflicting surface area of both claims-i. e., within the parallelogram c-x-e-f. The contention of the Jefferson company was that the Anchoria-Leland rights in the secondary vein $a-b$ should be defined by constructing a plane parallel to the end-line (e-f), at the point $X$, where the secondary vein passed out of the north side-line of the Anchor. The AnchoriaLeland Co. claimed a right to all the ore in the secondary vein underneath the Anchor surface. The court upheld the claim of the Anchoria-Leland on the theory that the question

12 Ajax Gold Min. Co. v. Hilkey, 31 Colo. 131, 102 Am. St. Rep. 23, 72 Pac. 447, 450, 62 L. R. A. 555, 22 Morr. Min. Rep. 585. In a later case to be presently discussed the same court said: "But the supreme court of the United States has gone further, and said that these bounding planes must be coincident witl the planes of the end-lines." 75 Pac., at p. 1075.

1332 Colo. 176, 75 Pac. 1070, 64 I. R. A. 925. 
involved the intralimital rather than the extralateral rights of the Anchor claim, and that claim being senior in point of time, secured all underground parts of the secondary vein underneath the surface, though such parts extended beyond a plane parallel to its end-lines drawn at the point on the side boundary where the apex of the secondary vein crossed such boundary at the point $X$ and entered the territory of the junior claim.

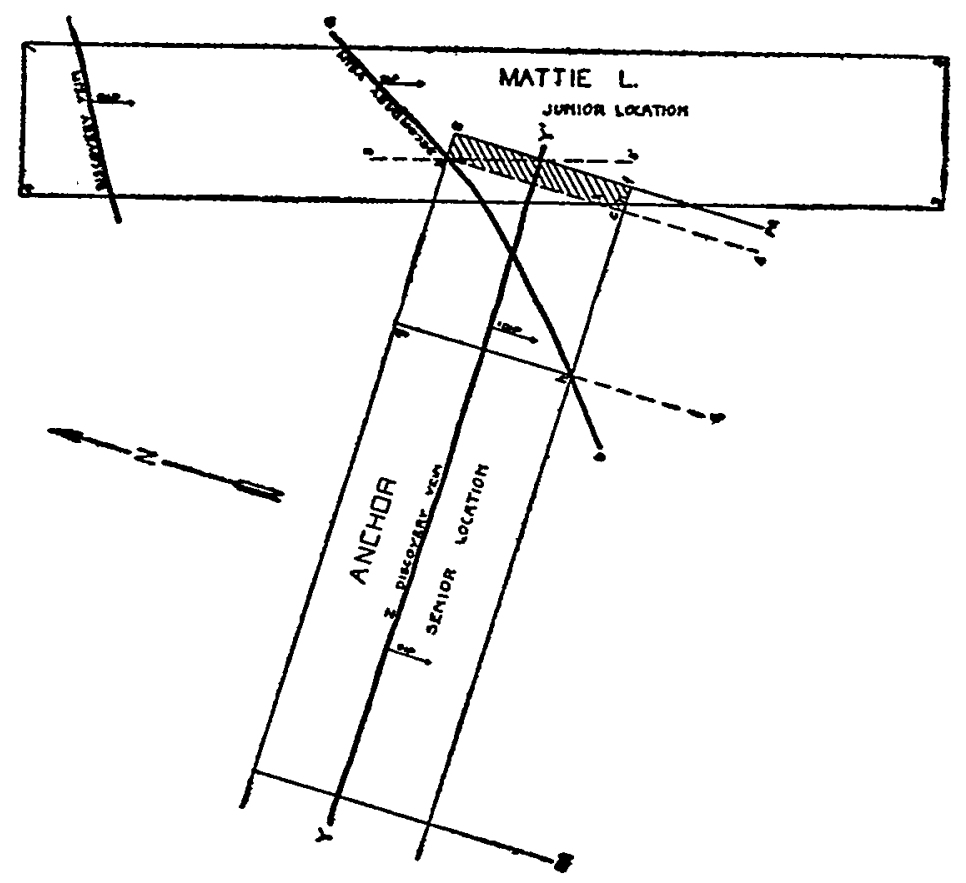

Figure No. 2.

The right of a claim owner to the underground parts of a vein beneath the surface may in a sense be referred to as intralimital. A prior locator on the dip of the vein without any part of the apex being within his boundaries may be said to have an intralimital right to the underground parts of the vein, and may defend such right as against everyone except the owner of a location properly including the apex. But such 
intralimital right fades away in the presence of one properly locating on the apex of the vein. So where the apex of a vein passes through an end-line and a side-line of one claim into another, the inquiry involves not only the intralimital rights of one, but also the extralateral rights of the other. For illustration take the Niagara-Black Rock case ${ }^{14}$ shown on Figure No. 3. The Black Rock was the older claim with part of the apex. The ore bodies in dispute were underneath the Black Rock surface beyond the point where the vein passed out of the side-line common to the two claims. Such ore bodies were in a sense intralimital to the Black Rock, but extralateral to the Niagara. As we have heretofore noted, the state court and the supreme court of the United States in effect denied to the Black Rock any intralimital rights on that portion of the vein underneath its surface extending beyond the point where the apex crossed the side-line, awarding such underground parts to the Niagara-the junior claim-under its extralateral right.

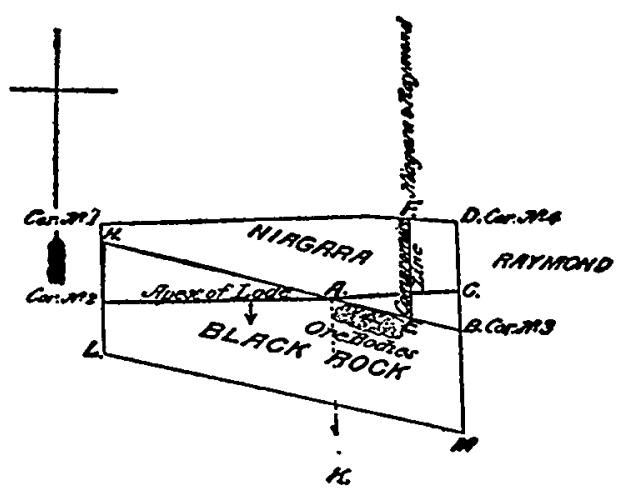

Figure No. 3.

The case of Davis v. Shepherd, ${ }^{15}$ decided by the supreme court of Colorado prior to its decisions in Ajax v. Hilkey and

11 Fitzgerald v. Clark 17 Mont. 100, 42 Pac. 273; on appeal Clark v. Fitzgerald 171 U. S. 92.

1531 Colo. 141, 72 Pac. 57. 
Jefferson v. Anchoria-Leland-applied the principle of the Niagara-Black Rock case to the original vein-apexing for a long distance in the junior claim and passing into the senior claim. The facts of this case may be illustrated by a diagram prepared from the record in the case, which we herewith reproduce as Figure No. 4.

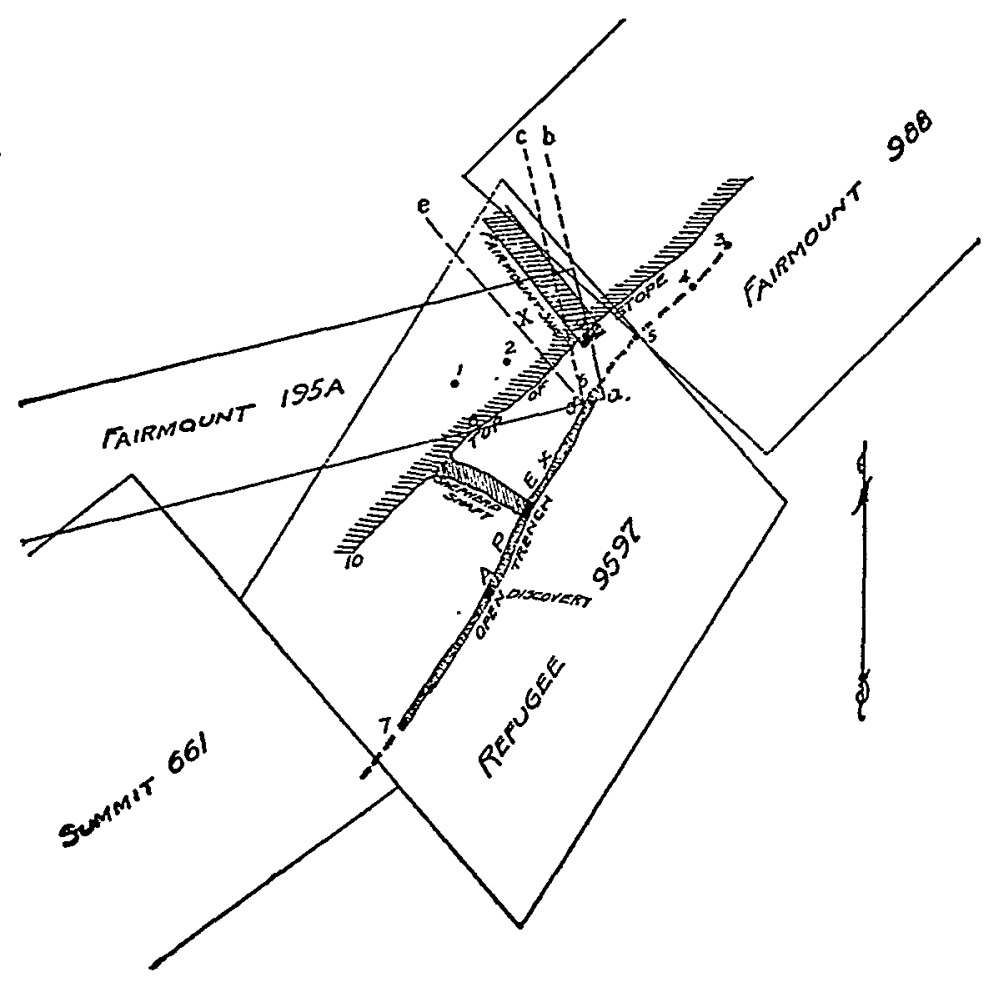

Figure No. 4.

The Fairmount 195A was the prior location, having been patented prior to the location of the Refugee. The apex of the vein was in the Refugee for the greater part of the length of the claim-a small segment of the apex being found in the corner of the Fairmount entering across a side-line and passing out of an end-line. The controversy arose over 
ore bodies stoped out by the Fairmount, being part of the vein having the apex within the Refugee. The court held that all that part of the vein which apexed without the boundaries of the Fairmount was not a part of that property.

Assuming the facts to be correctly portrayed on Figure No. 4. The extralateral right of the Fairmount would, upon the principles heretofore discussed, be defined by the planes $a-b$ and $c-d$. The extralateral right of the Refugee would be defined by the plane d-e and the west end-line plane, assuming that the apex did not extend to or cross the east end-line. The triangle $\mathrm{X}$ would, on this hypothesis, fall to the Fairmount by gravity as a prima facie intralimital right, owing to the difference in direction of the end-line planes of the two properties. If we may assume that the vein crossed both end-lines of the Refugee applying the principles announced in the Stemwinder cases, ${ }^{16}$ the extralateral right of the Refugee would be defined by the extension of its two end-line planes substracting thereform the segment of the vein pertaining to the Fairmount defined by the planes $a-b$ and $c-d$.

If the right of a senior claimant on an original vein is thus limited-and that it is so limited is now well settledwe cannot understand by what process of reasoning the courts may award a greater right upon a secondary vein.

In deciding the Jefferson-Anchoria-Leland case, the court referred to its ruling in Ajax Gold Min. Co. v. Hilkey, supra but held that it was inapplicable, because the rule followed in that case was so limited by reason of the fact that the counsel for Ajax company was content to accept it, and did not ask for any part of the vein beyond what the application of the rule there announced would give his clients.

With all possible deference to the distinguished court which rendered the two decisions, both of which were written by the same judge, we submit that the rule in the Ajax-Hilkey case is consistent with the decisions of the supreme court of the United States in the Del Monte case and the NiagaraBlack Rock case, and the prior decision of the supreme court

16 Bunker. Hill etc. Co. v. Empire State etc. Co., 109 Fed. 538; 114 Fed. 420; see also 121 Fed. 973; 131 Fed. 591. 
of Colorado in Davis v. Sheperd. If any support can be found in the adjudicated cases for the rule laid down in the Jefferson-Anchoria case, it is in what we conceive to be a misinterpretation of the decisions in the Walrath-Champion case, the doctrine of which the Colorado court in the Jefferson-Anchoria-Leland case held it was not necessary to invoke.

The application of the doctrine of the Stemwinder cases $^{17}$ together with the support which may be drawn from the Del Monte case $^{18}$ and the Niagara-Black Rock case, ${ }^{19}$ would certainly have given to the Mattie $\mathrm{L}$. the ore bodies within the parallelogram (fig. 2) X-ef-c, deducting the small triangle $c-k-n$, which was outside of and beyond the west side end boundary of the Niattie L.

An extrajudicial suggestion has been made to the effect that the extralateral right of the Mattie $L$. on the vein a-b should be defined by the plane s-s' drawn through the point $\mathrm{X}$ parallel to the Mattre $\mathrm{L}$. west side-line, upon the "free-apex" theory. In our opinion, however, the suggestion is opposed to the doctrine of the Stemwinder cases, where there are conflicting surface areas embracing the same apex. In such cases the formula for determining the extralateral right of a junior apex claimant may be stated as follows: Construct extralateral right planes on the junior claim as if there were no conflict, subtract the segment of the vein to which the senior is entitled. The remainder belongs to the junior claim. If the extralateral right of a senior claimant on the original vein is to be determined by the length of apex within the claim, and this is the rule clearly established in the NiagaraBlack Rock case, it can hardly be plausibly urged that greater rights should be awarded upon a secondary vein. We think

17 Bunker Hill \& S. M. \& M. Co. v. Empire State-Idaho M. \& D. Co., 109 Fed. 538, 547, 48 C. C. A. 665, 21 Morr. Min. Rep. 317, 134 Fed. 268; 121 Fed. 973, 58 C. C. A. 311, 22 Morr. Min. Rep. 560; S. C., on appeal, 131 Fed. $591,596,66$ C. C. A. 99; appeal dismissed, 200 U. S. 613,26 Sup. Ct. Rep. 754, 50 I. ed. 620; certiorari denied, 200 U. S. 617, 26 Sup. Ct. Rep. 754, 50 I. ed. 622.

18 Del Monte M. \& M. Co. v. Iast Chance M. \& M. Co., 171 U. S. 55, 18 Sup. Ct. Rep. 895, 43 I. ed. 72, 19 Morr. Min. Rep. 370.

19 Fitzgerald v. Clark, 17 Mont. 100, 52 Am. St. Rep. 665, 42 Pac. 273, 30 I. R. A. 803; Clark v. Fitzgerald, 171 U. S. 92, 18 Sup. Ct. Rep. 941,43 L. ed. 87 . 
the decision in Ajax M. Co. v. Hilkey states the correct rule. ${ }^{20}$

It will be borne in mind that the Del Monte, the NiagaraBlack Rock and the Walrath-Champion cases were decided by the supreme court of the United States at the same term and within eight days of each other. It is certainly not to be inferred that the Walrath-Champion case was intended by the court to overrule or qualify the epoch-making decisions in the other two cases. The opinion in the Walrath case negatives any such intent.

In the case of Work M. \& M. Co. v. Doctor Jack Pot M. Co., decided by the circuit court of appeals for the eighth circuit ${ }^{21}$ the question of extralateral rights in secondary veins was directly involved. The facts of the case may be illustrated by a diagram prepared from the record in the case (Figure No. 5.)

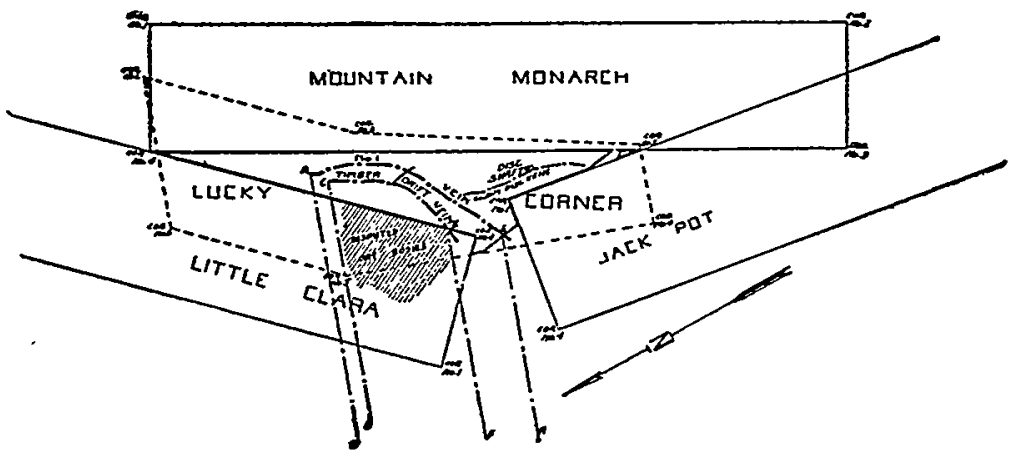

Figure No. 5.

${ }^{20} \mathrm{Mr}$. Costigan, in his work on "Mining Law," entertains the same view as the author as to the decision in the Jefferson-Anchoria Leland case. Costigan, p. 441, note 112 . Mr. Morrison, in the fourteenth edition of his "Mining Riglits," inclines to the view that Ajax v. Hilkey was wrongly decided, and that Jefferson v. Anchoria-Leland stated the correct rule. Morrison Min. Rights, 14th ed., 203. Mr. Arnold, in an elaborate discussion of this case found in volume 22, Harvard Law Review, pp. 339, 343, 349, arrives at the same conclusion as expressed by the author.

21194 Fed. 620. 
The net area of the Lucky Corner as patented embraced a surface in form resembling a triangle-delineated on Figure No. 5 by the heavier black line. It was located originally in the form indicated by the dotted lines, practically all of which were laid upon adjoining claims. The application for patent itself described the periphery of the claim as located and excepted the conflicts with other claims. The end-lines on the discovery vein as located were parallel. There were two secondary veins practically parallel to each other in the shape of crescent, neither of which were shown to have crossed either end-line of the claim as located. Their position is shown approximately on Figure No. 5. The controversy arose over the ore bodies in the secondary vein underneath the Little Clara. The court applied planes parallel to the endlines on the discovery vein at the points where the secondary veins terminated within the location substantially as indicated on the figure.

The court followed the rule announced by the supreme court of Colorado, in the Ajax-Hilkey case, quoting at length from the opinion. but made no reference to the decision in Jefferson M. Co. v. Anchoria-Leland M. \& M. Co.

CURTIS H. LINDLEY.

San Francisco, California. 